\title{
Use of high-flow nasal cannula oxygenation in ICU adults: a narrative review
}

\author{
Laurent Papazian ${ }^{1,2^{*}}$, Amanda Corley ${ }^{3}$, Dean Hess ${ }^{4}$, John F. Fraser ${ }^{3}$, Jean-Pierre Frat ${ }^{5,6}$, Christophe Guitton ${ }^{7}$, \\ Samir Jaber ${ }^{8}$, Salvatore M. Maggiore", Stefano Nava ${ }^{10}$, Jordi Rello ${ }^{11}$, Jean-Damien Ricard ${ }^{12,13,14}$, \\ François Stephan ${ }^{15}$, Rocco Trisolini ${ }^{16}$ and Elie Azoulay ${ }^{17}$
}

\begin{abstract}
Oxygen therapy can be delivered using low-flow, intermediate-flow (air entrainment mask), or high-flow devices. Low/intermediate-flow oxygen devices have several drawbacks that cause critically ill patients discomfort and translate into suboptimal clinical results. These include limitation of the $\mathrm{FiO}_{2}$ (due to the high inspiratory flow often observed in patients with respiratory failure), and insufficient humidification and warming of the inspired gas. Highflow nasal cannula oxygenation (HFNCO) delivers oxygen flow rates of up to $60 \mathrm{~L} / \mathrm{min}$ and over the last decade its effect on clinical outcomes has widely been evaluated, such as in the improvement of respiratory distress, the need for intubation, and mortality. Mechanisms of action of HFNCO are complex and not limited to the increased oxygen flow rate. The main aim of this review is to guide clinicians towards evidence-based clinical practice guidelines. It summarizes current knowledge about HFNCO use in ICU patients and the potential areas of uncertainties. For instance, it has been recently suggested that HFNCO could improve the outcome of patients with hypoxemic acute respiratory failure. In other settings, research is ongoing and additional evidence is needed. For instance, if intubation is required, studies suggest that HFNCO may help to improve preoxygenation and can be used after extubation. Likewise, HFNCO might be used in obese patients, or to prevent respiratory deterioration in hypoxemic patients requiring bronchoscopy, or for the delivery of aerosol therapy. However, areas for which conclusive data exist are limited and interventions using standardized HFNCO protocols, comparators, and relevant clinical outcomes are warranted.
\end{abstract}

Keywords: High-flow nasal cannula oxygenation, Oxygen therapy, Acute respiratory failure, Bronchoscopy, Aerosol, Non-invasive ventilation

\section{Introduction}

Oxygen therapy is the first-line treatment in hypoxemic patients. Oxygen can be delivered using low-flow devices (up to $15 \mathrm{~L} / \mathrm{min}$ ) such as nasal cannulas, non-rebreathing

\footnotetext{
*Correspondence: laurent.papazian@ap-hm.fr

${ }^{1}$ Réanimation des Détresses Respiratoires et Infections Sévères, Assistance Publique-Hôpitaux de Marseille, Hôpital Nord, Chemin des Bourrely, 13015 Marseille, France

Full author information is available at the end of the article
}

Take-home message: High-flow nasal cannula oxygenation has recently received resounding evidence of its efficacy in patients with hypoxemic acute respiratory failure. In other settings research is ongoing and additional evidence is needed. masks, and bag valve masks. The fraction of inspired oxygen $\left(\mathrm{FiO}_{2}\right)$ obtained using these devices varies with the oxygen flow and with the patient's peak inspiratory flow, delivery system, and device characteristics [1]. With conventional intermediate-flow systems, such as air entrainment masks, pressurized oxygen is forced through a small orifice at a constant flow, and this adds room air through entrainment ports, at a set air/oxygen ratio. However, if the patient has a high inspiratory flow, additional air is entrained around the mask and dilutes the oxygen, thereby lowering the $\mathrm{FiO}_{2}$. Conventional delivery devices have several drawbacks in addition to the limitation of the $\mathrm{FiO}_{2}$ that restrain their efficacy and tolerance such as 
insufficient humidification and insufficient warming of the inspired gas at high flows that cause patient discomfort $[2,3]$.

Twenty years ago, Dewan and Bell described their experience with 'high flows' delivered using a regular nasal cannula in patients with chronic obstructive pulmonary disease [4]. Over the past two decades, devices that deliver heated and humidified oxygen at high flows through a nasal cannula were developed as an alternative to low/intermediate-flow devices. High-flow nasal cannula oxygenation (HFNCO) delivers oxygen flows of up to $60 \mathrm{~L} / \mathrm{min}$. The gas source (air/oxygen blender, ventilator, or turbine flow-generator) is connected via an active heated humidifier to a nasal cannula and allows $\mathrm{FiO}_{2}$ adjustment independently from the flow (Fig. 1). Recently published studies suggested that HFNCO is a valuable tool in enhancing patients' comfort and oxygenation, and it could be associated with better outcomes [5-7]. We summarize here the current knowledge about HFNCO use in ICU patients and the potential areas of uncertainties.

\section{Principles and mechanisms of action of high-flow nasal cannula oxygen therapy}

The main mechanisms of action are summarized in Table 1. HFNCO therapy generates a flow-dependent $\mathrm{FiO}_{2}$ [7]. The more the flow is increased, the more the $\mathrm{FiO}_{2}$ is augmented. From 15 to $45 \mathrm{~L} / \mathrm{min}$ oxygen flow, tracheal $\mathrm{FiO}_{2}$ increases from 60 to $90 \%$ [8]. HFNCO maintains high $\mathrm{FiO}_{2}$ by delivering flows higher than the spontaneous inspiratory demand, thereby diminishing room-air entrainment, which occurs commonly with standard nasal cannulas and face masks. Among all other oxygen delivery devices, only the air entrainment mask at its maximum flow can deliver stable $\mathrm{FiO}_{2}$ values across a wide range of respiratory rates [9]. As the difference between the patients' inspiratory flow and the delivered flow is small with $\mathrm{HFNCO}, \mathrm{FiO}_{2}$ remains relatively stable. However, the flow rate must be set to match the patients' inspiratory demand and/or the severity of respiratory distress.

Two other important categories of mechanisms of action underpinning the reported clinical benefits of HFNCO are proposed. The first mechanism is related

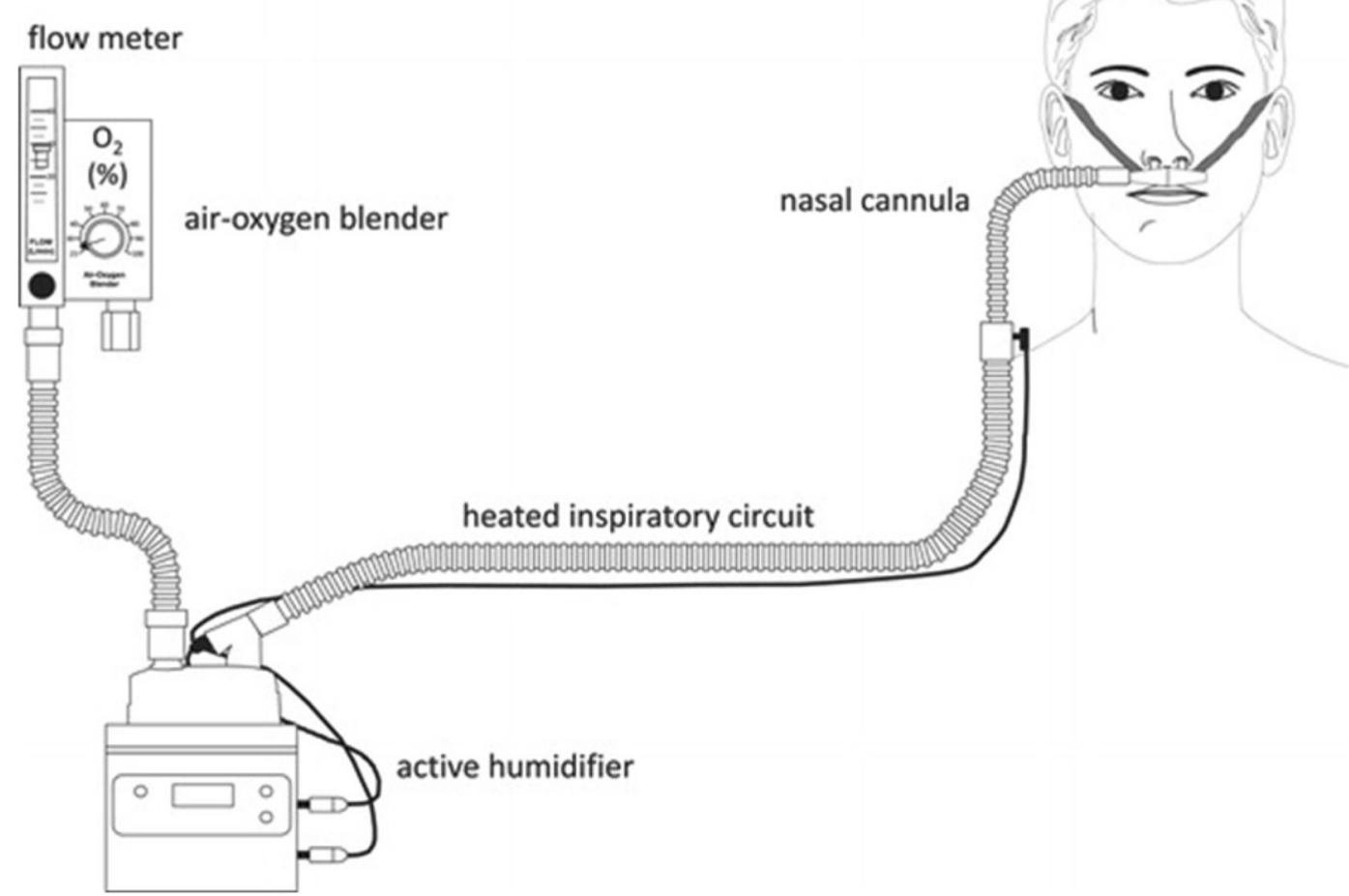

Fig. 1 High-flow nasal cannula oxygenation (HFNCO) device. An air/oxygen blender, allowing $\mathrm{FiO}_{2}$ ranging from 0.21 to 1.0, generates flows of up to $60 \mathrm{~L} / \mathrm{min}$. The gas is heated and humidified by an active heated humidifier and delivered via a single limb 


\section{Table 1 Physiological benefits of high-flow nasal cannula oxygenation (HFNCO) compared to conventional oxygen ther- apy}

$\mathrm{FiO}_{2}$ values are higher and more stable

Because the delivered flow is higher than the spontaneous inspiratory demand and because the difference between the delivered flow rate and the patient's inspiratory flow rate is smaller

The flow must be set to match the patient's inspiratory demand and/or the severity of the respiratory distress

The anatomical dead space is decreased via washout of the nasopharyngeal space

Consequently, a larger fraction of the minute ventilation participates in gas exchange

Respiratory efforts become more efficient

Thoracoabdominal synchrony improves

he work of breathing is decreased

Because HFNCO mechanically stents the airway

Provides flow rates that match the patient's inspiratory flow, and markedly attenuates the inspiratory resistance associated with the nasopharynx,

thereby reducing the work of breathing

The gas delivered is heated and humidified

Warm humid gas reduces the work of breathing and improves mucociliary function, thereby facilitating secretion clearance, decreasing the risk of

atelectasis, and improving the ventilation/perfusion ratio and oxygenation

The body is spared the energy cost of warming and humidifying the inspired gas (neonates +++ )

Warm humid gas is associated with better conductance and pulmonary compliance compared to dry, cooler gas

HFNCO delivers adequately warmed and humidified gas only when the flow is $>40 \mathrm{~L} / \mathrm{min}$

Positive airway pressures are increased

The nasal cannula generates continuous positive pressures in the pharynx of up to $8 \mathrm{cmH}_{2} \mathrm{O}$, depending or flow and mouth opening

The positive pressure distends the lungs, ensuring lung recruitment and decreasing the ventilation-perfusion mismatch in the lungs

End-expiratory lung volume is greater with HFNO than with low-flow oxygen therapy

Minimizing leaks around the cannula prongs is of the utmost importance

to optimal conditioning of the delivered gas because the nasal air/oxygen mixtures are warmed and humidified closely to physiological conditions [2, 8]. Thus, oxygen flow is better tolerated and provides greater respiratory comfort especially with flows up to $60 \mathrm{~L} / \mathrm{min}$ $[2,8]$. The second mechanism is related to high-flow delivery ( $>30 \mathrm{~L} / \mathrm{min}$ ). HFNCO therapy generates a flowdependent positive airway pressure $[8,10]$. At $35 \mathrm{~L} /$ min, the mean airway pressure measured with a nasopharyngeal catheter was $1.2 \pm 0.8 \mathrm{cmH}_{2} \mathrm{O}$, mouth open, increasing up to $2.7 \pm 1.0 \mathrm{~cm} \mathrm{H}_{2} \mathrm{O}$, mouth closed and to $3.3 \pm 1.0 \mathrm{cmH}_{2} \mathrm{O}$ at $50 \mathrm{~L} / \mathrm{min}[11,12]$. A physiological study demonstrated lower pressures with HFNCO with the highest median value below $2.5 \mathrm{cmH}_{2} \mathrm{O}$ at $45 \mathrm{~L} / \mathrm{min}$, mouth closed [8]. This difference between studies could be explained by airway pressure measurement inside the trachea [8], more distal from the device, rather than in the nasopharynx [11] and decreased airway pressure when patients breath with an open mouth $[8,13]$. This should be taken into account when HFNCO is used in critically ill patients with acute respiratory failure (ARF), who often breath through an open mouth rather than through the nose. It has also been shown that HFNCO is associated with an increased end-expiratory lung impedance in a cohort of postcardiac surgery patients, suggestive of increased lung volumes and functional residual capacity [14]. In obese postcardiac surgery patients with higher body mass index (BMI), the increase in end-expiratory lung volume (EELV) was found to be significantly greater when HFNCO was used as compared with lowflow oxygen therapy [14]. This increase in EELV may be interpreted as the recruitment of alveoli, and prevention of further alveolar collapse, as a result of the lowlevel positive pressure generated by HFNCO. The higher $\mathrm{PaO}_{2} / \mathrm{FiO}_{2}$ reported in patients using HFNCO could be attributed in part to the observed increase in EELV and resultant increase in alveolar ventilation. The clearance of $\mathrm{CO}_{2}$ in anatomic dead space also contributed to the improvement in subjective dyspnea and decrease in respiratory rate [15]. This increase in end-expiratory lung impedance is also influenced by the position. Riera et al. [16] reported that HFNCO in healthy subjects in the supine position produced regional improvement in endexpiratory lung impedance of the lung ventral regions that was significantly higher than in the dorsal regions. This observation was not shown when subjects were in the prone position, in whom end-expiratory lung impedance distribution was more homogeneous. However, it is generally acknowledged that non-intubated patients look more comfortable when supine or in the semirecumbent position than in the prone position. Although the positive airway pressure generated by HFNCO is moderate $[8,11$, 
12], it could partially counteract intrinsic PEEP leading to decreased work of breathing and improved comfort [17] in patients exhibiting dynamic hyperinflation.

HFNCO also allows a clearing of airway dead space $[6,18]$. The ability to continually flush out $\mathrm{CO}_{2}$ from the upper airway is another potential benefit of HFNCO. It increases alveolar ventilation [4]. However, this effect reaches a plateau above a threshold flow rate corresponding to complete washout of the nasopharyngeal dead space.

Respiratory inductance plethysmography demonstrated that thoracoabdominal synchrony could be improved with HFNCO as compared with face mask oxygen therapy [19]. Furthermore, HFNCO was associated with a lower respiratory rate while tidal volume was maintained, indicating a decrease in minute ventilation $[7,14,19,20]$. Available data suggest that HFNCO is an effective method for delivering oxygen therapy. In comparison to conventional low-flow oxygen devices, HFNCO allows an improvement of gas exchange, respiratory rate, and comfort. HFNCO seems safer than face mask, with less interface displacement and less oxygen desaturations [6].

Finally, unique features of HFNCO lie in its simplicity of use [21]; its remarkable tolerance and comfort [5-7, $20,22-24]$ in comparison with other forms of oxygen delivery, including noninvasive ventilation (NIV) $[5,22$, 25], and its practicality in terms of oxygen and ventilation equipment management.

\section{High-flow nasal cannula for acute respiratory failure}

Acute respiratory failure is one the leading reasons for ICU admission. The main studies related to the use of HFNCO in ARF are detailed in Table 2. Based on limited numbers of patients and without control groups, these studies lacked strong primary outcomes such as avoidance of intubation and reduced mortality. They were nonetheless instrumental in forming the basis for a large multicenter randomized study such as FLORALI [22]. The principal indication for HFNCO in the ICU is hypoxemic ARF whose main etiology is communityacquired pneumonia, from bacterial or viral origin $[7,20$, $22,24,26]$. An important question is whether the severity of hypoxemia is a limitation to the use of HFNCO. A recent study reporting the use of HFNCO in severe ARDS [24] showed that failure (i.e., need for intubation) rate of $\mathrm{HFNCO}$ was $40 \%$, similar to the $35 \%$ reported in the subgroup of patients with a severe hypoxemia $\left(\mathrm{PaO}_{2} / \mathrm{FiO}_{2} \leq 200 \mathrm{mmHg}\right)$ reported in the FLORALI study [22]. On the basis of observational studies showing the improvement of many patients treated with HFNCO, associated with the reported failure rates mentioned above, it was suggested that HFNCO was able to prevent intubation in some patients. There was, however, no convincing proof of intubation avoidance by HFNCO until recently. Indeed, the FLORALI study is therefore pivotal in demonstrating the superiority of HFNCO over both conventional oxygenation and NIV [22]. The significant reduction in mortality in the group of patients treated with HFNCO weakens the use of NIV in hypoxemic ARF and suggests that HFNCO should be the first-line strategy in these patients [22]. As NIV may delay intubation and increase mortality [27], a similar concern was raised with HFNCO; one recent study reported such an association [28]. A closer analysis of the literature indicates that this may not be the case if the decision to intubate is taken within 24-48 h following HFNCO initiation [29] and supported by prespecified criteria for intubation [5, $22,24]$. The ensuing question is how to predict failure. The use of accessory muscles [7] and persistence of high respiratory rates $[5,7]$ and distress thoracoabdominal asynchrony are indicative of an unsatisfactory response to HFNCO that should lead one to consider intubation. Studies have suggested that more than the severity of the respiratory disease per se, presence of an additional organ failure such as hemodynamic instability places the patients at higher risk of failure [24, 26].

There is now some evidence that HFNCO has a central place in the armamentarium of ARF management. Its unique features allow it to be used from admission to discharge. However, there is the need for confirmatory trials in order to show that HFNCO is indubitably able to improve the outcome of ARF patients.

\section{Use of high-flow nasal cannula in immunocompromised patients}

Because mortality in immunocompromised patients with hypoxemic ARF is significantly higher compared to unselected patients, respiratory management that aims to avoid intubation and invasive mechanical ventilation is of major interest. Five studies have reported feasibility and safety of HFNCO in selected groups of immunocompromised patients with ARF. In a retrospective single-center study, Lee et al. [30] reported the feasibility of HFNCO for treating ARF in 45 patients with hematologic malignancies. HFNCO was titrated at an $\mathrm{FiO}_{2}$ sufficient to maintain the arterial $\mathrm{O}_{2}$ saturation level at greater than $90 \%$ and a flow of up to $45-50 \mathrm{~L} /$ min [30]. Fifteen (33\%) patients successfully recovered without intubation and their mortality was lower compared to intubated patients [30]. HFNCO failure was associated with the diagnosis of bacterial pneumonia [30]. In another study of ARF patients outside the ICU, Epstein et al. [31] reported a $72 \%$ HFNCO use among 183 patients with solid tumors. Among these patients, 


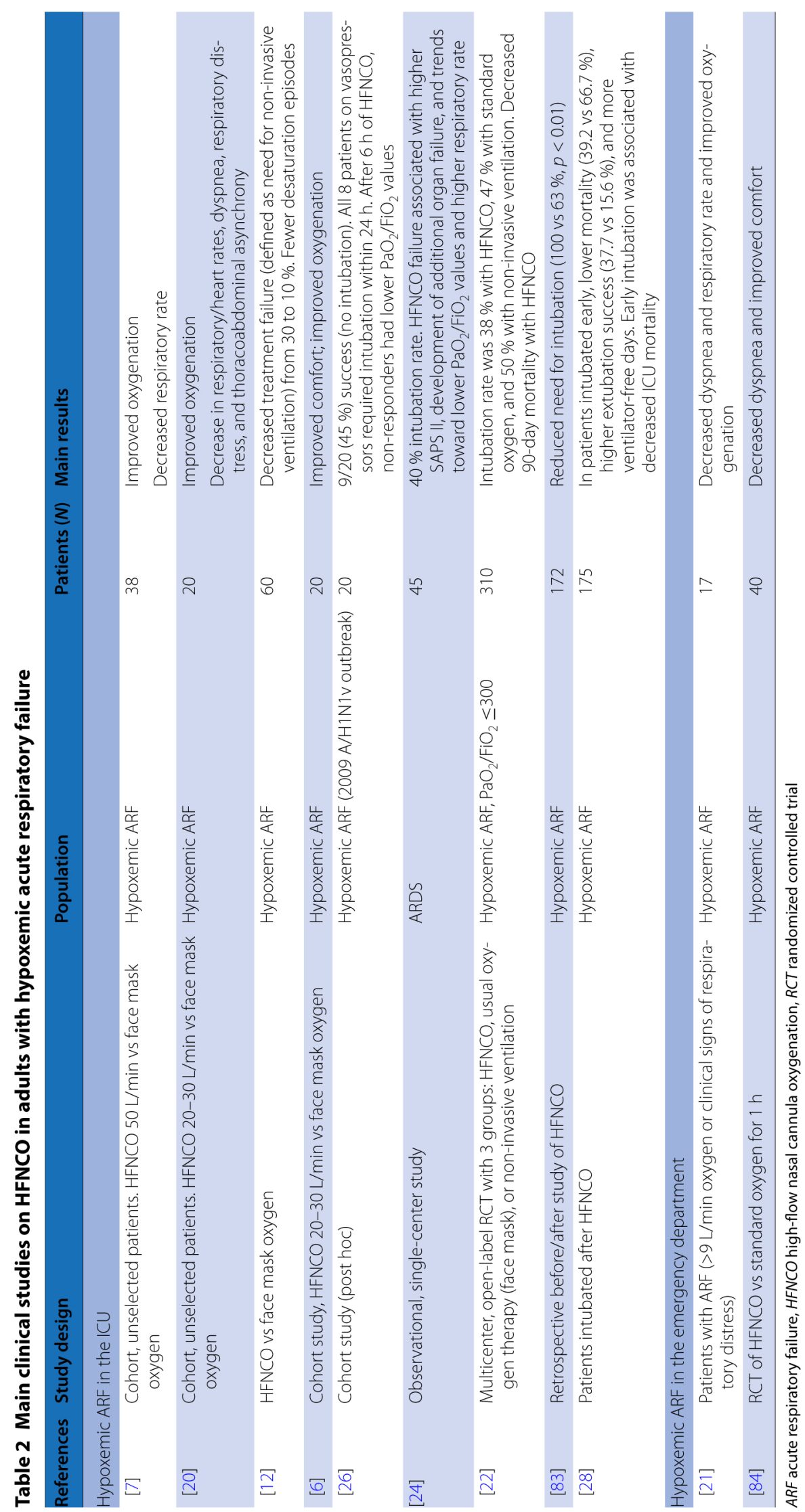


$41 \%$ improved, $44 \%$ stabilized, and $15 \%$ worsened. In a pilot randomized physiological trial, 30 patients with advanced cancer and persistent dyspnea were assigned either to HFNCO or NIV for $2 \mathrm{~h}$ [32]. Dyspnea (VAS and modified Borg scale), vital signs, and adverse effects were measured before and after the intervention. Dyspnea was significantly improved by both HFNCO and NIV, with no difference between the two techniques [32]. Oxygen saturation was only improved by HFNCO and there was a trend for a non-significant decrease in respiratory rate by both techniques. No significant adverse effects were observed [32]. In 37 critically ill lung transplant patients, Roca et al. reported that HFNCO was feasible and safe to treat ARF [33]. The absolute risk reduction for mechanical ventilation with HFNCO was $29.8 \%$, and the number of patients needed to treat to prevent one intubation with HFNCO was 3 [33]. Last, in a study of 50 do-not-intubate patients with hypoxemic respiratory distress, including mostly immunocompromised patients [34], HFNCO allowed an improvement in oxygenation and decreased respiratory rate. The survival benefits from HFNCO was also assessed in different groups of immunocompromised patients. The first study analyzed 178 cancer patients with $\operatorname{ARF}\left(\mathrm{O}_{2}>9 \mathrm{~L} / \mathrm{min}\right)$, including $76(43 \%)$ treated with NIV and HFNCO, 74 (42\%) with NIV and standard oxygen therapy, 20 (11\%) with HFNCO alone, and 8 with standard oxygen therapy alone. Patients receiving the combination of HFNCO and NIV exhibited lower mortality rates (37 vs $52 \%, p=0.04$ ) [35]. In the propensity analysis, HFNCO associated with NIV was independently associated with improved 28-day survival [35]. This is in sharp contrast with the results of the substudy from the FLORALI trial where HFNCO allowed survival benefits but HFNCO combined with NIV was associated with significant increased 28-day mortality [22]. Last, in a substudy from the iVNIctus trial [36] that investigated benefits from early NIV in immunocompromised patients with ARF, 141/374 (38\%) patients received HFNCO and other patients received either oxygen only or NIV. A propensity score using variables available at ICU admission was built to allow adjustments. Intubation rate and 28-day mortality were not significantly different in immunocompromised patients treated with HFNCO as compared to NIV or standard oxygen [36].

All these studies and discrepant results confirm feasibility and safety of HFNCO in immunocompromised patients and demonstrate at least equipoise between HFNCO, NIV, and standard oxygen therapy in this setting. They also warrant future trials to demonstrate that survival benefits reported in unselected patients with hypoxemic ARF extend to immunocompromised patients.

\section{High-flow nasal cannula oxygen use preceding endotracheal intubation (Table 3)}

Endotracheal intubation (ETI) is a routinely performed ICU procedure notably for patients with ARF [37]. ETI is frequently associated with morbidity, or even mortality. Almost $30 \%$ of ETI are associated with serious adverse events. The most frequently reported complication $(26 \%)$ is severe desaturation under $80 \%$, notably for hypoxemic patients [38]. Preoxygenation before ETI is a crucial stage permitting one to delay desaturation. Oxygenation through a high-flow facial bag valve mask is usually recommended. However, in ICU, especially in severe ARF, efficiency of preoxygenation is lessened with a high prevalence of desaturations due to patients' instability [39]. Even if NIV usefulness in preoxygenation has been reported, no large randomized multicenter study has confirmed this assumption [40]. Because use of this device has to be interrupted during laryngoscopy, NIV fails to totally prevent desaturation during ETI. A recent single-center trial compared non-rebreathing bag reservoir facial mask to HFNCO for preoxygenation before ETI [41]. This before-after study included patients $(n=101)$ regardless of the reasons for intubation. Patients with severe hypoxemia were excluded from this study. Concerning the primary outcome, the median (IQR) lowest $\mathrm{SpO}_{2}$ reached during ETI was $100 \%$ (95-100 \%) in the HFNCO group as compared to $94 \%$ $(83-98.5 \%)(p<0.0001)$ for the facial mask [41]. The prevalence of desaturation events $(<80 \%)$ decreased from $14 \%$ in the facial mask group to $2 \%$ in the HFNCO group $(p=0.03)$ [41]. These encouraging results were not confirmed by a subsequent randomized controlled trial, comparing HFNCO $(n=62)$ to high-flow facial bag valve mask $(n=57)$ for preoxygenation (and apneic oxygenation) in severe hypoxemic patients [42]. These discordant results could be explained by differences regarding both the reasons for intubation and the severity of hypoxemia at inclusion. An additional recent trial [43] evaluated the effect of supplemental oxygenation by HFNCO during laryngoscopy (vs no oxygenation) in 150 critically ill patients. Median lowest arterial oxygen saturation was $92 \%$ with apneic oxygenation with HFNCO vs $90 \%$ with usual care without oxygen supplementation $(p=0.16)$. No difference was reported regarding the incidence of oxygen saturation $<90 \%$, or $<80 \%$, or decrease in oxygen saturation $>3 \%$. The literature suggests that despite interesting properties, the place of HFNCO for preoxygenation during ETI is still not clear. We are waiting for further large trials to ultimately conclude on its accuracy in ICU, in comparison with NIV or standard oxygen therapy, especially for severely hypoxemic patients. 


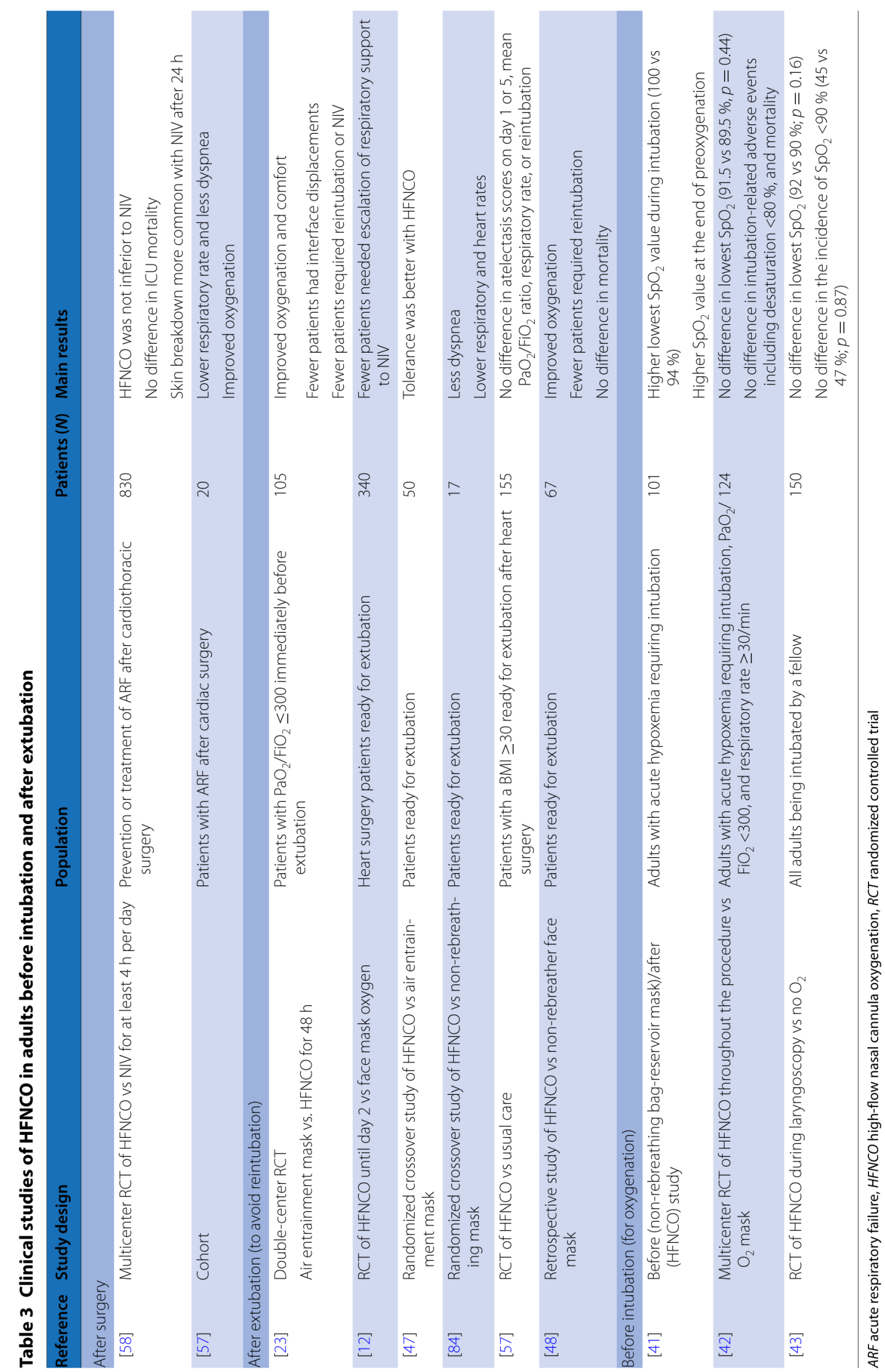




\section{High-flow nasal cannula use following extubation (Table 3)}

\section{In the ICU}

Atelectasis may persist up to $24-48 \mathrm{~h}$ after extubation following anesthesia and paralysis even in patients with healthy lungs [44]. Oxygen therapy is almost invariably used after extubation to correct the residual oxygenation impairment. Because of its positive effects on the respiratory system, HFNCO is an appealing device to reverse postextubation atelectasis and improve oxygenation [45]. Few studies have been published to date on the use of HFNCO after extubation. HFNCO after extubation decreased dyspnea score, breathing frequency, and heart rate as compared with a non-rebreathing mask [46]. However, in a small randomized, crossover trial comparing high flow delivered with nasal cannula or face mask after extubation, no difference regarding gas exchange, respiratory rate, or hemodynamic parameters was reported [47]. A retrospective study compared the clinical effects of HFNCO and non-rebreathing mask in 67 critically ill patients after extubation [48]. The authors found a better oxygenation (measured as the $\mathrm{PaO}_{2}$ to the nominal $\mathrm{FiO}_{2}$ ratio) with $\mathrm{HFNCO}$, while $\mathrm{PaCO}_{2}$, respiratory rate, mean arterial pressure, and heart rate were not different among the two groups. In addition, the use of HFNCO was associated with a higher number of ventilator-free days $(4.14 \pm 2.2$ vs $3.0 \pm 2.0)$ and a lower reintubation rate ( 2.9 vs $18.2 \%$ ) [48]. A recent randomized controlled trial comparing the effects of the air entrainment mask (52 patients) and HFNCO (53 patients) in patients presenting a moderate hypoxemia (i.e., $\mathrm{PaO}_{2} /$ $\mathrm{FiO}_{2} \leq 300$ immediately before extubation) [23] showed that HFNCO improved oxygenation. In addition, HFNCO decreased $\mathrm{PaCO}_{2}$ and respiratory rate, suggesting a reduction in the upper airways dead space. The use of HFNCO improved patients' discomfort both related to the interface (from the 12th hour) and to symptoms of airway dryness (from the 24th hour), and was associated with fewer episodes of interface displacement and oxygen desaturation [23]. Most importantly, fewer patients had postextubation respiratory failure requiring any form of ventilator support (7.5 vs $34.6 \%$ ) with less need for NIV (3.8 vs $15.4 \%$ ) and endotracheal reintubation ( 3.8 vs $21.2 \%$ ) with HFNCO than with the air entrainment mask [23]. This study, however, was not aimed at demonstrating the superiority of the HFNCO over the entrainment mask in the weaning outcome [23]. These authors, therefore, designed a multicenter randomized controlled trial (RINO trial) to assess whether, as compared with the entrainment mask, the use of HFNCO might reduce the extubation failure rate in patients with moderate hypoxemia after extubation (ClinicalTrials.gov: NCT02107183). Few multicenter randomized controlled trials have been performed to evaluate the effectiveness of HFNCO after extubation but are still not published. Finally, HFNCO may play a role in preventing reintubation in moderately hypoxemic patients, although further studies are needed to better define which patients can benefit the most and the optimal timing of application. Findings of ongoing randomized trials will hopefully help to answer these questions.

\section{Following surgery}

The rate of hypoxemia following surgery is frequent and as high as $52 \%$ in patients after cardiothoracic surgery [49]. The first treatment of hypoxemia is to provide lowflow oxygen therapy. When low-flow oxygen therapy is insufficient, NIV is often used in the postoperative setting [50] delaying intubation with HF. NIV fails in about $20 \%$ of patients after cardiothoracic surgery, who then require reintubation [51, 52]. In patients presenting with hypoxemic respiratory failure, a single randomized trial found that NIV after lung resection decreased the rate of intubation, from 50.0 to $20.8 \%$, and also decreased mortality [51]. Both reintubation and mortality rates decreased significantly with NIV in the single published randomized study after heart surgery [53]. As a preventive strategy, a randomized controlled trial after major lung resection in COPD patients did not improve the rate of ARF, but decreased the rate of ARF requiring NIV [54]. Following cardiac surgery, prophylactic use of NIV improved oxygenation and reduced incidence of pulmonary complications [55]. There are few published studies on the use of HFNCO during the postoperative period. In a pragmatic randomized controlled trial of routine HFNCO in cardiac surgery patients, HFNCO was not associated with an increase in oxygenation compared with usual oxygen therapy, but it was associated with a reduced requirement for escalation of therapy and a slightly lower $\mathrm{PaCO}_{2}$ [56]. In the same way, prophylactic extubation using HFNCO in postcardiac surgery patients with a BMI $\geq 30 \mathrm{~kg} /$ $\mathrm{m}^{2}$ did not lead to improvement in respiratory function [57]. Recently, in a multicenter, randomized, non-inferiority, open trial, including 830 patients, the use of continuous HFNCO compared with intermittent NIV did not result in a worse rate of treatment failure [risk difference $=0.86 \%$ (95\% CI -4.9 to 6.6)] [58]. The $\mathrm{PaO}_{2} /$ $\mathrm{FiO}_{2}$ improved in the two groups but to a lesser extent for HFNCO. Both the $\mathrm{PaCO}_{2}$ level and the respiratory rate decreased more rapidly in patients treated by HFNCO [58]. Interestingly there was no difference for the dyspnea or the comfort scores. Skin breakdown was significantly more common with NIV after $24 \mathrm{~h}$ [58]. In a post hoc analysis of this study [59], the authors reported that preventive postextubation NIV was associated with a higher rate of failure in high-risk patients treated as compared 
with HFNCO (12.6 vs $5.7 \%$, respectively). For many postoperative hypoxemic patients, HFNCO appears to be a valuable alternative to NIV [58]. For patients with moderate to severe hypercapnia NIV is still the best choice. Finally, as with NIV, HFNCO should be applied in a safe environment with close monitoring. Indeed, as it has been reported with NIV [60], delaying intubation with HFNCO could lead to a worse outcome [28].

\section{Use of high-flow nasal cannula in specific conditions}

\section{Aerosol delivery by high-flow nasal cannula}

Some in vitro studies have been done regarding the performance of aerosol therapy during HFNCO [61]. It has been shown that with oxygen (or heliox), there is an important decrease in the delivered dose with an increase in flow from 3 to $6 \mathrm{~L} / \mathrm{min}$ [62]. However, flows commonly used for $\mathrm{HFNCO}$ in adults are $30-50 \mathrm{~L} / \mathrm{min}$. Perry et al. [63] evaluated the in vitro albuterol delivery and particle size with a mesh nebulizer and HFNCO. The inspired dose (\% of nominal dose) for each cannula size and flow was $2.5,0.8,0.4$, and $0.2 \%$ for the adult cannula at $5,10,20$, and $40 \mathrm{~L} / \mathrm{min}$, respectively. The effects of nebulizer type, nebulizer position, flow (30,45, and $60 \mathrm{~L} / \mathrm{min}$ ), breathing pattern (quiet and respiratory distress), and opened and closed mouth was also assessed in another in vitro study [64]. The most efficient placement of the nebulizer was upstream from the humidifier. With a mesh nebulizer, the respirable mass ranged from 2 to $10 \%$ of the nebulizer charge. Higher flows and an open mouth were associated with a lower efficiency. Simulated respiratory distress did not hinder drug delivery. When simulating a mean inspiratory flow of $45 \mathrm{~L} / \mathrm{min}$ with an HFNCO flow of $60 \mathrm{~L} / \mathrm{min}$, and using a mesh nebulizer upstream of the humidifier, the average inhaled mass of respirable aerosol was $5 \%$ of the nominal dose. A reasonable estimate of usual aerosol delivery by mouthpiece is $15 \%$ of the nominal dose, or $0.375 \mathrm{mg}$ of a $2.5-\mathrm{mg}$ nominal dose, which is much greater than that reported by Perry et al. [63]. But the benefit of albuterol delivery by HFNCO might be for continuous aerosol bronchodilator $(\mathrm{CAB})$ in the setting of severe acute asthma. Imagine that HFNCO is used with $C A B$ set to deliver $15 \mathrm{mg}$ albuterol per hour for an adult with HFNCO set at $5 \mathrm{~L} /$ min. According to the results of Perry et al. [63], this would deliver $0.375 \mathrm{mg} / \mathrm{h}-$ exactly the same amount estimated for a single treatment by mouthpiece. According to the data of Réminiac et al. [64], the delivered dose would be $0.75 \mathrm{mg} / \mathrm{h}$ at HFNCO flows of $60 \mathrm{~L} / \mathrm{min}$, which is greater than that typically administered with a single treatment. HFNCO for $\mathrm{CAB}$ might be more acceptable to the patient, and might more convenient for the healthcare provider, than hourly mouthpiece treatments. This is encouraging for the use of HFNCO for aerosol delivery, but needs to be confirmed in clinical studies.

With HFNCO, much aerosol is lost due to impaction in the circuit and into the ambient environment. One approach to this problem uses separate streams of submicrometer aerosol and heated humidified air to the right and left nostrils [65]. Evaporating the output of an aerosol generator creates submicrometer aerosol. There is a subsequent increase to particle size when mixed with the heated and humidified gas beyond the nose. This coadministration of heated humidified gas, as used with the HFNCO, causes the enhanced condensational growth of the aerosol to the respirable size range. Another approach delivers a submicrometer aerosol in combination with a hygroscopic excipient [65]. With the combination of drug and hygroscopic excipient particles, when the aerosol is exposed to the natural humidity of the respiratory system, excipient-enhanced growth occurs, producing droplets of a size suitable for deposition in the lungs. Longest et al. [66] used in vitro experiments and simulations to evaluate the feasibility of enhanced condensational growth with a nasal cannula. They found that it might be possible to use a nasal cannula with delivery efficiencies of 80 to $90 \%$. Submicrometer particles with enhanced condensational growth delivery resulted in lower depositional losses. Using an in vitro model, Golshahi et al. [65] found that aerosol delivery using realistic breathing profiles of submicrometer condensational growth aerosols was efficient in delivering nasally administered drugs. These approaches might allow high aerosol dose delivery by HFNCO. The available in vitro evidence is not sufficiently robust to recommend for or against aerosol delivery with HFNCO. At high flows, the amount of aerosol delivery might be low. Enhanced condensational growth and excipient-enhanced growth have the potential to improve the feasibility of aerosol delivery with HFNCO. Clinical studies are necessary to inform the use of HFNCO for aerosol delivery as part of patient care.

\section{Bronchoscopy during high-flow nasal cannula use}

Bronchoscopy is associated with temporary alterations of gas exchange, lung mechanics, and hemodynamics caused by a variety of mechanisms, such as reduction of alveolar ventilation, increase of ventilation-perfusion mismatch, increase of cardiac output and oxygen consumption [67]. The bronchoscope occupies approximately $10 \%$ of the cross-sectional area of the trachea, and this leads to a $10-30 \%$ decrease in arterial $\mathrm{PaO}_{2}$ despite low-flow oxygen administration, as compared to its baseline value [68, 69]. In patients with hypoxemia, the risks associated with bronchoscopy, especially during a BAL, are significantly enhanced, specifically worsening 
of gas exchange and cardiovascular events [70]. A number of randomized trials demonstrated that continuous positive airway pressure (CPAP) and NIV are better means of preventing deterioration of gas exchange than conventional sources of oxygen in patients with respiratory failure undergoing bronchoscopy $[69,71]$. The success of these methods depends, however, on the tolerance of the interface that in some patients may be poor, and also on the difficulty for the operator to insert and direct the bronchoscope, which must pass through an orifice of the interface that is not necessarily in the proximity of the nose or mouth of the patient $[69,71]$. Given its capacity to ameliorate hypoxemia in patients with ARF, HFNCO is, theoretically, a potentially simpler means of preventing worsening hypoxemia during bronchoscopy [72]. In a randomized trial, Lucangelo et al. [73] evaluated the effect of bronchoscopy with BAL on gas exchange and cardiovascular variables in 45 patients receiving $40 \mathrm{~L} /$ min of oxygen through air entrainment mask, $40 \mathrm{~L} / \mathrm{min}$ through HFNCO, or $60 \mathrm{~L} / \mathrm{min}$ through HFNCO. Being a pilot study the inclusion criteria (i.e., $\mathrm{SpO}_{2} \geq 90 \%$ and absence of respiratory or cardiac failure) were quite conservative. The procedures were completed in a standard endoscopy suite, and conscious sedation was achieved in all patients with a low dose of midazolam. Patients receiving $\mathrm{HFNCO}$ at $60 \mathrm{~L} / \mathrm{min}$ through $\mathrm{HFNCO}$ had better $\mathrm{PaO}_{2}, \mathrm{PaO}_{2} / \mathrm{FiO}_{2}$, and $\mathrm{SpO}_{2}$ than those receiving $40 \mathrm{~L} /$ min through air entrainment mask or HFNCO. No differences were seen in the aforementioned variables among patients receiving $40 \mathrm{~L} / \mathrm{min}$ through air entrainment mask or HFNCO. Simon et al. [74] evaluated the effect of HFNCO in a small cohort of patients with a more severe respiratory involvement $\left(\mathrm{PaO}_{2} / \mathrm{FiO}_{2}<165\right.$ in all patients) during bronchoscopy with BAL. In this study, 40 critically ill patients with hypoxemic respiratory failure were randomized to receive either NIV or HFNCO (set at an oxygen flow of $50 \mathrm{~L} / \mathrm{min}$ ). The procedures were completed in the ICU and the amount of sedation given (96 and $74 \mathrm{mg}$ of propofol in the HFNCO and NIV group, respectively) was significantly higher than that in the study by Lucangelo et al. [73]. The lowest oxygen saturation recorded by pulse oxymetry during bronchoscopy was the primary outcome measure. Oxygen levels were significantly higher in the NIV group than in the HFNCO group both during and after bronchoscopy, but 19/20 patients in the HFNCO group successfully completed the procedure with no complications.

In conclusion, the limited available data does not establish decision-making pathways to guide use of the HFNCO therapy to prevent gas exchange deterioration in hypoxemic patients requiring bronchoscopy. Further research is required to assess the predictors of success and failure of NHFC during bronchoscopy, and to identify the patient population in whom it is most beneficial. A large prospective, observational multicenter trial (NCT02523573) is currently being conducted to evaluate efficacy and tolerance of HFNCO in ICU patients admitted for ARF requiring BAL.

\section{Use of high-flow nasal cannula in obese patients}

Global obesity levels, having doubled since the 1980s, now exceed 600 million persons [75]. Respiratory alterations specifically associated with obesity include a reduced functional residual capacity (FRC) which exponentially decreases as body mass indices (BMI) increase $[76,77]$. Therefore, the majority of breathing occurs on the less compliant part of the pressure-volume curve, encroaching on closing volume. Ventilation-perfusion mismatch and hypoxemia ensue with increased ventilatory requirements necessitating higher inspiratory flows [78]. Increased upper airway resistance and collapsibility due to the mechanical load imposed particularly by central obesity are also seen [77]. Increased work of breathing due to pressure exerted by the abdomen, reduced respiratory compliance, and increased metabolic demands of the respiratory muscles resulting in respiratory muscle inefficiency have also been reported [79]. Considering the physiologic rationale for HFNCO and understanding the etiology of obesity-induced respiratory dysfunction, it seems reasonable that HFNCO might provide some clinical benefit for these patients. Obesityinduced FRC reductions may be partially reversed by the combination of both CPAP generated by HFNCO [14, 80] and increased EELV [14]. Hence, breathing returns to the more compliant part of the pressure-volume curve leading to improvements in respiratory efficiency, compliance, and ventilation-perfusion mismatch. PEEP may also assist in upper airway splinting thereby reducing the airway collapsibility of central obesity. Through a constant high flow of oxygen-rich gas, HFNCO reduces anatomical dead space leading to improved respiratory efficiency due to increased alveolar ventilation [45]. Moreover, HFNCO more accurately matches the inspiratory flow demands of the obese patient by providing flows of up to $60 \mathrm{~L} / \mathrm{min}$. This may result in a reduction in inspiratory resistance and, consequently, work of breathing [81]. Less entrainment of room air results in higher delivered $\mathrm{FiO}_{2}$ thereby meeting the increased oxygen requirements of the morbidly obese patient in particular.

Whilst we can postulate on how the mechanisms of action of HFNCO may benefit the obese patient, data specific to HFNCO use in these patients is very limited. In a postcardiac surgery observational study comparing HFNCO with low-flow oxygen, higher BMI was associated with larger increases in EELV [14]. At a BMI of $25 \mathrm{~kg} / \mathrm{m}^{2}$, a mean increase in EELV of $13.3 \%$ was seen 
with HFNCO. However, EELV increased by $24.4 \%$ at a BMI of $40 \mathrm{~kg} / \mathrm{m}^{2}$. This finding led to a randomized controlled trial investigating the efficacy of HFNCO in reducing postoperative atelectasis seen in the obese patient [57]. Direct extubation to HFNCO was compared with standard oxygen therapy in postcardiac surgery patients with a BMI $\geq 30 \mathrm{~kg} / \mathrm{m}^{2}$. A total of 155 patients were randomized to receive either HFNCO up to $50 \mathrm{~L} /$ min or standard oxygen therapy $(2-6 \mathrm{~L} / \mathrm{min})$ for at least $8 \mathrm{~h}$ postextubation. HFNCO did not improve atelectasis, oxygenation, respiratory rate, patient-rated dyspnea, or failure of allocated therapy when tested in a randomized controlled fashion. Heinrich et al. [82] conducted a randomized controlled trial in 33 patients investigating three preoxygenation techniques prior to rapid sequence induction in morbidly obese patients undergoing bariatric surgery. HFNCO $\left(50 \mathrm{~L} / \mathrm{min}\right.$ at $\left.\mathrm{FiO}_{2} 1.0\right)$ was compared with CPAP $\left(7 \mathrm{cmH}_{2} \mathrm{O}\right.$ at $\mathrm{FiO}_{2}$ 1.0) and standard treatment $\left(12 \mathrm{~L} / \mathrm{min}\right.$ via face mask at $\left.\mathrm{FiO}_{2} 1.0\right)$, and the primary outcome was $\mathrm{PaO}_{2}$. HFNCO significantly improved $\mathrm{PaO}_{2}$ at 5 and $7 \mathrm{~min}$ of the preoxygenation/ induction period compared with standard treatment and provided comparable oxygenation to CPAP. The authors concluded that HFNCO was a feasible and safe method of preoxygenation in this cohort. However, given the paucity of data, targeted investigation of the clinical utility of HFNCO in obese patients must take place before their efficacy in this cohort can be determined.

\section{Uncertainties about high-flow nasal cannula oxygen therapy}

A growing body of evidence suggests that HFNCO therapy may be effective for the early treatment of adults with respiratory failure. However, the few areas for which conclusive data exist and those requiring further investigation need to be stressed. At least five points deserve attention. First, the wide variability in inclusion criteria creates considerable heterogeneity among published studies. For instance, studies of patients with hypoxemia included all patients with hypoxemia, patients with hypoxemia and respiratory distress, or patients with a $\mathrm{PaO}_{2} / \mathrm{FiO}_{2}<300$. Second, the primary endpoints used in some studies were improvements in physiological variables (oxygenation or lung volumes), which do not always translate into better clinical outcomes (less respiratory distress, less intubation, or better survival). Third, the HFNCO parameters (flow, $\mathrm{FiO}_{2}$, time of HFNCO exposure) varied in most studies, precluding an assessment of a possible dose-response effect. Fourth, the magnitude of the benefits from HFNCO (odds ratio) on the various endpoints (oxygenation, comfort, intubation, or survival) varied markedly across studies. This point is related to the previous one, as dose may influence the effect size.
Furthermore, the time of endpoint evaluation also varied. Finally, and importantly, a variety of comparators have been used, including low-flow oxygen, air entrainment mask, and NIV. This last point is a major source of bias and reflects the current uncertainty about what should be the reference or "standard" for oxygen therapy in patients with acute hypoxemia.

These considerations emphasize the importance of using clinical endpoints such as the intubation rate or mortality, rather than physiological endpoints such as $\mathrm{SpO}_{2}$ or $\mathrm{PaO}_{2} / \mathrm{FiO}_{2}$.

A fundamental difference between HFNCO and NIV is that HFNCO systems maintain a fixed flow and generate variable pressures, whereas many NIV systems use a variable flow to generate a fixed pressure, precluding the manipulation of alveolar ventilation. Another major difference is that the anatomical dead space is increased by NIV interfaces and decreased by HFNCO interfaces. While NIV is able to increase tidal volume, HFNCO has no direct effect on this parameter. Nevertheless, HFNCO helps patients by improving alveolar ventilation and decreasing the anatomical dead space.

HFNCO may play a role in preventing extubation failure and might improve clinical outcomes in patients with hypoxemic respiratory failure or prevent hypoxemia in selected patients at high risk. There is, however, the need for additional trials in order to target the patients who should be treated with HFNCO, either in preventing intubation and following extubation. Finally, we must keep in mind that delaying intubation with HFNCO could lead to a worse outcome [28].

In summary, HFNCO improves the outcome of patients with hypoxemic ARF. In other settings, research is ongoing and additional evidence is needed. For instance, if intubation is required, studies suggest that HFNCO may help to improve preoxygenation and can be used after extubation. Likewise, HFNCO might be used in obese patients, or to prevent respiratory deterioration in hypoxemic patients requiring bronchoscopy, or for the delivery of aerosol therapy. However, areas for which conclusive data exist are limited and interventions using standardized HFNCO protocols, comparators, and relevant clinical outcomes are warranted.

\section{Author details}

Réanimation des Détresses Respiratoires et Infections Sévères, Assistance Publique-Hôpitaux de Marseille, Hôpital Nord, Chemin des Bourrely, 13015 Marseille, France. ${ }^{2}$ URMITE UMR CNRS 7278, Faculté de Médecine, Aix-Marseille Université, 13005 Marseille, France. ${ }^{3}$ Critical Care Research Group The Prince Charles Hospital and University of Queensland, Brisbane, Australia. ${ }^{4}$ Respiratory Care Department of the Massachusetts General Hospital and the Department of Anesthesia at the Harvard Medical School, Boston, MA, USA. ${ }^{5}$ CHU de Poitiers, Réanimation Médicale, Poitiers, France. ${ }^{6}$ INSERM, CIC-1402, Université de Poitiers, Poitiers, France. ${ }^{7}$ Medical ICU, Hôtel-Dieu, University Hospital of Nantes, Nantes, France. ${ }^{8}$ Department of Critical Care 
Medicine and Anesthesiology (DAR B), Research Unit INSERM U1046, Saint Eloi University Hospital and Montpellier School of Medicine, 80 Avenue Augustin Fliche, 34295 Montpellier, France. ${ }^{9}$ Department of Anesthesiology and Critical Care Medicine, Policlinico SS. Annunziata, Università degli Studi "Gabriele d'Annunzio" Chieti-Pescara, Via dei Vestini, 31, 66100 Chieti, Italy. ${ }^{10}$ Department of Specialist, Diagnostic and Experimental Medicine, School of Medicine, Respiratory and Critical Care, Sant'Orsola, Malpighi Hospital, Università di Bologna, Bologna, Italy. ${ }^{11}$ Medicine Department, CIBERES, Universitat Autonoma de Barcelona, Ps Vall d'Hebron 119, Anexe AG-5a Planta, 08035 Barcelona, Spain. ${ }^{12}$ AP-HP, Hôpital Louis Mourier, Service de Réanimation Médico-Chirurgicale, 178 rue des Renouillers, 92700 Colombes, France. ${ }^{13}$ INSERM, IAME, UMR 1137 , 75018 Paris, France. ${ }^{14}$ IAME, UMR 1137, Sorbonne Paris Cité, Université Paris Diderot, 75018 Paris, France. ${ }^{15}$ Service de Réanimation adulte, Hôpital Marie Lannelongue, 133 Avenue de la Résistance, 92350 Le Plessis-Robinson, France. ${ }^{16}$ Interventional Pulmology, Sant'Orsola, Malpighi Hospital, Bologna, Italy. ${ }^{17}$ AP-HP, Hôpital Saint-Louis, Service de Réanimation Médicale, Sorbonne Paris Cité, Paris Diderot University, Paris, France.

\section{Compliance with ethical standards}

\section{Conflicts of interest}

Amanda Corley: unrestricted grant and travel expenses from Fisher and Paykel Healthcare; John F. Fraser: unrestricted grant and travel expenses from Fisher and Paykel Healthcare; Dean Hess: Philipps, Respironics, Bayer, Merck, Up To Date, McGraw-Hill, Jones and Bartlett, and the American Board of Internal Medicine; Jean-Damien Ricard: travel expenses from Fisher and Paykel Healthcare; Jean-Pierre Frat: travel expenses from Fisher and Paykel Healthcare; Stefano Nava: grant from Fisher and Paykel Healthcare; Salvatoire M. Maggiore: unrestricted research grant from Fisher and Paykel Healthcare; François Stephan: lecture fees from Fisher and Paykel Healthcare.

\section{Financial support}

No financial support.

\section{References}

1. Bazuaye EA, Stone TN, Corris PA, Gibson GJ (1992) Variability of inspired oxygen concentration with nasal cannulas. Thorax 47:609-611

2. Chanques G, Constantin JM, Sauter M, Jung B, Sebbane M, Verzilli D, Lefrant JY, Jaber S (2009) Discomfort associated with under humidified high-flow oxygen therapy in critically ill patients. Intensive Care Med 35:996-1003

3. Cuquemelle E, Pham T, Papon JF, Louis B, Danin PE, Brochard L (2012) Heated and humidified high-flow oxygen therapy reduces discomfort during hypoxemic respiratory failure. Respir Care 57:1571-1577

4. Dewan NA, Bell CW (1994) Effect of low flow and high flow oxygen delivery on exercise tolerance and sensation of dyspnea. A study comparing the transtracheal catheter and nasal prongs. Chest 105:1061-1065

5. Frat JP, Brugiere B, Ragot S, Chatellier D, Veinstein A, Goudet V, Coudroy R, Petitpas F, Robert R, Thille AW, Girault C (2015) Sequential application of oxygen therapy via high-flow nasal cannula and noninvasive ventilation in acute respiratory failure: an observational pilot study. Respir Care 60:170-178

6. Roca O, Riera J, Torres F, Masclans JR (2010) High-flow oxygen therapy in acute respiratory failure. Respir Care 55:408-413

7. Sztrymf B, Messika J, Bertrand F, Hurel D, Leon R, Dreyfuss D, Ricard JD (2011) Beneficial effects of humidified high flow nasal oxygen in critical care patients: a prospective pilot study. Intensive Care Med 37:1780-1786

8. Chanques G, Riboulet F, Molinari N, Carr J, Jung B, Prades A, Galia F, Futier E, Constantin JM, Jaber S (2013) Comparison of three high flow oxygen therapy delivery devices: a clinical physiological cross-over study. Minerva Anestesiol 79:1344-1355

9. WagstaffTA, Soni N (2007) Performance of six types of oxygen delivery devices at varying respiratory rates. Anaesthesia 62:492-503

10. Mundel T, Feng S, Tatkov S, Schneider H (2013) Mechanisms of nasal high flow on ventilation during wakefulness and sleep. J Appl Physiol 114:1058-1065
11. Parke RL, Eccleston ML, McGuinness SP (2011) The effects of flow on airway pressure during nasal high-flow oxygen therapy. Respir Care 56:1151-1155

12. Parke RL, McGuinness SP (2013) Pressures delivered by nasal high flow oxygen during all phases of the respiratory cycle. Respir Care 58:1621-1624

13. Groves N, Tobin A (2007) High flow nasal oxygen generates positive airway pressure in adult volunteers. Aust Crit Care 20:126-131

14. Corley A, Caruana LR, Barnett AG, Tronstad O, Fraser JF (2011) Oxygen delivery through high-flow nasal cannulae increase end-expiratory lung volume and reduce respiratory rate in post-cardiac surgical patients. $\mathrm{Br}\rfloor$ Anaesth 107:998-1004

15. Schmidt M, Banzett RB, Raux M, Morelot-Panzini C, Dangers L, Similowski T, Demoule A (2014) Unrecognized suffering in the ICU: addressing dyspnea in mechanically ventilated patients. Intensive Care Med 40:1-10

16. Riera J, Perez P, Cortes J, Roca O, Masclans JR, Rello J (2013) Effect of highflow nasal cannula and body position on end-expiratory lung volume: a cohort study using electrical impedance tomography. Respir Care 58:589-596

17. Vargas F, Saint-Leger M, Boyer A, Bui NH, Hilbert G (2015) Physiologic effects of high-flow nasal cannula oxygen in critical care subjects. Respir Care 2015:03814

18. Moller W, Celik G, Feng S, Bartenstein P, Meyer G, Oliver E, Schmid O, Tatkov S (2015) Nasal high flow clears anatomical dead space in upper airway models. J Appl Physiol 118:1525-1532

19. Itagaki T, Okuda N, Tsunano Y, Kohata H, Nakataki E, Onodera M, Imanaka H, Nishimura M (2014) Effect of high-flow nasal cannula on thoracoabdominal synchrony in adult critically ill patients. Respir Care 59:70-74

20. Sztrymf B, Messika J, Mayot T, Lenglet H, Dreyfuss D, Ricard JD (2012) Impact of high-flow nasal cannula oxygen therapy on intensive care unit patients with acute respiratory failure: a prospective observational study. J Crit Care 27:324.e9-324.e13

21. Lenglet H, Sztrymf B, Leroy C, Brun P, Dreyfuss D, Ricard JD (2013) Humidified high flow nasal oxygen during respiratory failure in the emergency department: feasibility and efficacy. Respir Care 57:1873-1878

22. Frat JP, Thille AW, Mercat A, Girault C, Ragot S, Perbet S, Prat G, Boulain T, Morawiec E, Cottereau A, Devaquet J, Nseir S, Razazi K, Mira JP, Argaud L, Chakarian JC, Ricard JD, Wittebole X, Chevalier S, Herbland A, Fartoukh M, Constantin JM, Tonnelier JM, Pierrot M, Mathonnet A, Beduneau G, Deletage-Metreau C, Richard JC, Brochard L, Robert R (2015) High-flow oxygen through nasal cannula in acute hypoxemic respiratory failure. $\mathrm{N}$ Engl J Med 372:2185-2196

23. Maggiore SM, Idone FA, Vaschetto R, Festa R, Cataldo A, Antonicelli F, Montini L, De Gaetano A, Navalesi P, Antonelli M (2014) Nasal highflow versus Venturi mask oxygen therapy after extubation. Effects on oxygenation, comfort, and clinical outcome. Am J Resp Crit Care Med 190:282-288

24. Messika J, Ben Ahmed K, Gaudry S, Miguel-Montanes R, Rafat C, Sztrymf B, Dreyfuss D, Ricard JD (2015) Use of high-flow nasal cannula oxygen therapy in subjects with ARDS: a 1-year observational study. Respir Care 60:162-169

25. Schwabbauer N, Berg B, Blumenstock G, Haap M, Hetzel J, Riessen R (2014) Nasal high-flow oxygen therapy in patients with hypoxic respiratory failure: effect on functional and subjective respiratory parameters compared to conventional oxygen therapy and non-invasive ventilation (NIV). BMC Anesthesiol 14:66

26. Rello J, Perez M, Roca O, Poulakou G, Souto J, Laborda C, Balcells J, Serra J, Masclans JR, CRIPS Investigators (2012) High-flow nasal therapy in adults with severe acute respiratory infection: a cohort study in patients with 2009 influenza A/H1N1v. J Crit Care 27:434-439

27. Carrillo A, Gonzalez-Diaz G, Ferrer M, Martinez-Quintana ME, LopezMartinez A, Llamas N, Alcazar M, Torres A (2012) Non-invasive ventilation in community-acquired pneumonia and severe acute respiratory failure. Intensive Care Med 38:458-466

28. Kang BJ, Koh Y, Lim CM, Huh JW, Baek S, Han M, Seo HS, Suh HJ, Seo GJ, Kim EY, Hong SB (2015) Failure of high-flow nasal cannula therapy may delay intubation and increase mortality. Intensive Care Med 41:623-632

29. Ricard JD, Messika J, Sztrymf B, Gaudry S (2015) Impact on outcome of delayed intubation with high-flow nasal cannula oxygen: is the device solely responsible? Intensive Care Med 41:1157-1158 
30. Lee HY, Rhee CK, Lee JW (2015) Feasibility of high-flow nasal cannula oxygen therapy for acute respiratory failure in patients with hematologic malignancies: a retrospective single-center study. J Crit Care 30:773-777

31. Epstein AS, Hartridge-Lambert SK, Ramaker JS, Voigt LP, Portlock CS (2011) Humidified high-flow nasal oxygen utilization in patients with cancer at Memorial Sloan-Kettering Cancer Center. J Palliat Med 14:835-839

32. Hui D, Morgado M, Chisholm G, Withers L, Nguyen Q, Finch C, FrisbeeHume S, Bruera E (2013) High-flow oxygen and bilevel positive airway pressure for persistent dyspnea in patients with advanced cancer: a phase II randomized trial. J Pain Symptom Manage 46:463-473

33. Roca O, de Acilu MG, Caralt B, Sacanell J, Masclans JR (2015) Humidified high flow nasal cannula supportive therapy improves outcomes in lung transplant recipients readmitted to the intensive care unit because of acute respiratory failure. Transplantation 99:1092-1098

34. Peters SG, Holets SR, Gay PC (2013) High-flow nasal cannula therapy in do-not intubate patients with hypoxemic respiratory distress. Respir Care 58:597-600

35. Mokart D, Geay C, Chow-Chine L, Brun JP, Faucher M, Blache JL, Bisbal M, Sannini A (2015) High-flow oxygen therapy in cancer patients with acute respiratory failure. Intensive Care Med 2015:4

36. Lemiale V, Mokart D, Resche-Rigon M, Pene F, Mayaux J, Faucher E, Nyunga M, Girault C, Perez P, Guitton C, Ekpe K, Kouatchet A, Theodose I, Benoit D, Canet E, Barbier F, Rabbat A, Bruneel F, Vincent F, Klouche K, Loay K, Mariotte E, Bouadma L, Moreau AS, Seguin A, Meert AP, Reignier J, Papazian L, Mehzari I, Cohen Y, Schenck M, Hamidfar R, Darmon M, Demoule A, Chevret S, Azoulay E, Groupe de Recherche en Reanimation Respiratoire du patient d'Onco-Hématologie (GRRR-OH) (2015) Effect of noninvasive ventilation vs oxygen therapy on mortality among immunocompromised patients with acute respiratory failure: a randomized clinical trial. JAMA 314:1711-1719

37. De Jong A, Molinari N, Terzi N, Mongardon N, Arnal JM, Guitton C, Allaouchiche B, Paugam-Burtz C, Constantin JM, Lefrant JY, Leone M, Papazian L, Asehnoune K, Maziers N, Azoulay E, Pradel G, Jung B, Jaber S, AzuRea Network for the Frida-Rea Study Group (2013) Early identification of patients at risk for difficult intubation in the intensive care unit: development and validation of the MACOCHA score in a multicenter cohort study. Am J Respir Crit Care Med 187:832-839

38. Jaber S, Amraoui J, Lefrant JY, Arich C, Cohendy R, Landreau L, Calvet Y, Capdevila X, Mahamat A, Eledjam JJ (2006) Clinical practice and risk factors for immediate complications of endotracheal intubation in the intensive care unit: a prospective, multiple-center study. Crit Care Med 34:2355-2361

39. Mort TC (2005) Preoxygenation in critically ill patients requiring emergency tracheal intubation. Crit Care Med 33:2672-2675

40. Baillard C, Fosse JP, Sebbane M, Chanques G, Vincent F, Courouble P, Cohen Y, Eledjam JJ, Adnet F, Jaber S (2006) Noninvasive ventilation improves preoxygenation before intubation of hypoxic patients. Am J Respir Crit Care Med 174:171-177

41. Miguel-Montanes R, Hajage D, Messika J, Bertrand F, Gaudry S, Rafat C, Labbe V, Dufour N, Jean-Baptiste S, Bedet A, Dreyfuss D, Ricard JD (2015) Use of high-flow nasal cannula oxygen therapy to prevent desaturation during tracheal intubation of intensive care patients with mild-to-moderate hypoxemia. Crit Care Med 43:574-583

42. Vourc'h M, Asfar P, Volteau C, Bachoumas K, Clavieras N, Egreteau PY, Asehnoune K, Mercat A, Reignier J, Jaber S, Prat G, Roquilly A, Brule N, Villers D, Bretonniere C, Guitton C (2015) High-flow nasal cannula oxygen during endotracheal intubation in hypoxemic patients: a randomized controlled clinical trial. Intensive Care Med 2015:14

43. Semler MW, Janz DR, Lentz RJ, Matthews DT, Norman BC, Assad TR, Keriwala RD, Ferrell BA, Noto MJ, McKown AC, Kocurek EG, Warren MA, Huerta LE, Rice TW, FELLOW Investigators, the Pragmatic Critical Care Research Group (2016) Randomized trial of apneic oxygenation during endotracheal intubation of the critically ill. Am J Respir Crit Care Med 193:273-280

44. Strandberg A, Tokics L, Brismar B, Lundquist H, Hedenstierna G (1986) Atelectasis during anaesthesia and in the postoperative period. Acta Anaesthesiol Scand 30:154-158

45. Lee JH, Rehder KJ, Williford L, Cheifetz IM, Turner DA (2013) Use of high flow nasal cannula in critically ill infants, children, and adults: a critical review of the literature. Intensive Care Med 39:247-257

46. Rittayamai N, Tscheikuna J, Rujiwit P (2014) High-flow nasal cannula versus conventional oxygen therapy after endotracheal extubation: a randomized crossover physiologic study. Respir Care 59:485-490
47. Tiruvoipati R, Lewis D, Haji K, Botha J (2010) High-flow nasal oxygen vs high-flow face mask: a randomized crossover trial in extubated patients. J Crit Care 25:463-468

48. Brotfain E, Zlotnik A, Schwartz A, Frenkel A, Koyfman L, Gruenbaum SE, Klein M (2014) Comparison of the effectiveness of high flow nasal oxygen cannula vs standard non-rebreather oxygen face mask in post-extubation intensive care unit patients. Isr Med Assoc J 16:718-722

49. Xue FS, Li BW, Zhang GS, Liao X, Zhang YM, Liu JH, An G, Luo LK (1999) The influence of surgical sites on early postoperative hypoxemia in adults undergoing elective surgery. Anesth Analg 88:213-219

50. Chiumello D, Chevallard G, Gregoretti C (2011) Non-invasive ventilation in postoperative patients: a systematic review. Intensive Care Med 37:918-929

51. Auriant I, Jallot A, Herve P, Cerrina J, Le Roy Ladurie F, Fournier JL, Lescot B, Parquin F (2001) Noninvasive ventilation reduces mortality in acute respiratory failure following lung resection. Am J Respir Crit Care Med 164:1231-1235

52. Jaber S, Chanques G, Jung B (2010) Postoperative noninvasive ventilation. Anesthesiology 112:453-461

53. Zhu F, Liu ZL, Long X, Wu XD, Zhou J, Bai CX, Li SQ (2013) Effect of noninvasive positive pressure ventilation on weaning success in patients receiving invasive mechanical ventilation: a meta-analysis. Chin Med J 126:1337-1343

54. Lorut C, Lefebvre A, Planquette B, Quinquis L, Clavier H, Santelmo N, Abou Hanna H, Bellenot F, Regnard JF, Riquet M, Magdeleinat P, Meyer G, Roche N, Huchon G, Coste J, Rabbat A, Revel MP (2014) Early postoperative prophylactic noninvasive ventilation after major lung resection in COPD patients: a randomized controlled trial. Intensive Care Med 40:220-227

55. Zarbock A, Mueller E, Netzer S, Gabriel A, Feindt P, Kindgen-Milles D (2009) Prophylactic nasal continuous positive airway pressure following cardiac surgery protects from postoperative pulmonary complications: a prospective, randomized, controlled trial in 500 patients. Chest 135:1252-1259

56. Parke R, McGuinness S, Dixon R, Jull A (2013) Open-label, phase Il study of routine high-flow nasal oxygen therapy in cardiac surgical patients. $\mathrm{Br} J$ Anaesth 111:925-931

57. Corley A, Bull T, Spooner AJ, Barnett AG, Fraser JF (2015) Direct extubation onto high-flow nasal cannulae post-cardiac surgery vs standard treatment in patients with a $\mathrm{BMI}>/=30$ : a randomised controlled trial Intensive Care Med 41:887-894

58. Stephan F, Barrucand B, Petit P, Rezaiguia-Delclaux S, Medard A, Delannoy B, Cosserant B, Flicoteaux G, Imbert A, Pilorge C, Berard L, BiPOP Study Group (2015) High-flow nasal oxygen vs noninvasive positive airway pressure in hypoxemic patients after cardiothoracic surgery: a randomized clinical trial. JAMA 313:2331-2339

59. Stephan $F(2015)$ High-flow nasal oxygen therapy for postextubation acute hypoxemic respiratory failure-reply. JAMA 314:1644-1645

60. Esteban A, Frutos-Vivar F, Ferguson ND, Arabi Y, Apezteguia C, Gonzalez M, Epstein SK, Hill NS, Nava S, Soares MA, D’Empaire G, Alia I, Anzueto A (2004) Noninvasive positive-pressure ventilation for respiratory failure after extubation. N Engl J Med 350:2452-2460

61. Hess DR (2015) Aerosol therapy during noninvasive ventilation or highflow nasal cannula. Respir Care 60:880-891 (discussion 891-883)

62. Ari A, Harwood R, Sheard M, Dailey P, Fink JB (2011) In vitro comparison of heliox and oxygen in aerosol delivery using pediatric high flow nasal cannula. Pediatr Pulmonol 46:795-801

63. Perry SA, Kesser KC, Geller DE, Selhorst DM, Rendle JK, Hertzog JH (2013) Influences of cannula size and flow rate on aerosol drug delivery through the Vapotherm humidified high-flow nasal cannula system. Pediatr Crit Care Med 14:e250-e256

64. Réminiac F, Vecellio L, Heuze-Vourc'h N, Petitcollin A, Respaud R, Cabrera $M$, Le Pennec D, Diot P, Ehrmann S (2015) Aerosol therapy in adults receiving high flow nasal cannula oxygen therapy. J Aerosol Med Pulm Drug Deliv. doi:10.1089/jamp.2015.1219

65. Golshahi L, Tian G, Azimi M, Son YJ, Walenga R, Longest PW, Hindle M (2013) The use of condensational growth methods for efficient drug delivery to the lungs during noninvasive ventilation high flow therapy. Pharm Res 30:2917-2930

66. Longest PW, Walenga RL, Son YJ, Hindle M (2013) High-efficiency generation and delivery of aerosols through nasal cannula during noninvasive ventilation. J Aerosol Med Pulm Drug Deliv 26:266-279 
67. Matsushima Y, Jones RL, King EG, Moysa G, Alton JD (1984) Alterations in pulmonary mechanics and gas exchange during routine fiberoptic bronchoscopy. Chest 86:184-188

68. Antonelli M, Conti G, Rocco M, Arcangeli A, Cavaliere F, Proietti R, Meduri GU (2002) Noninvasive positive-pressure ventilation vs conventional oxygen supplementation in hypoxemic patients undergoing diagnostic bronchoscopy. Chest 121:1149-1154

69. Maitre B, Jaber S, Maggiore SM, Bergot E, Richard JC, Bakthiari H, Housset B, Boussignac G, Brochard L (2000) Continuous positive airway pressure during fiberoptic bronchoscopy in hypoxemic patients. A randomized double-blind study using a new device. Am J Respir Crit Care Med 162:1063-1067

70. Papazian L, Colt HG, Scemama F, Martin C, Gouin F (1993) Effects of consecutive protected specimen brushing and bronchoalveolar lavage on gas exchange and hemodynamics in ventilated patients. Chest 104:1548-1552

71. Antonelli M, Pennisi MA, Conti G, Bello G, Maggiore SM, Michetti V, Cavaliere F, Proietti R (2003) Fiberoptic bronchoscopy during noninvasive positive pressure ventilation delivered by helmet. Intensive Care Med 29:126-129

72. Spoletini G, Alotaibi M, Blasi F, Hill NS (2015) Heated humidified high-flow nasal oxygen in adults: mechanisms of action and clinical implications. Chest 148:253-261

73. Lucangelo U, Vassallo FG, Marras E, Ferluga M, Beziza E, Comuzzi L, Berlot $G$, Zin WA (2012) High-flow nasal interface improves oxygenation in patients undergoing bronchoscopy. Crit Care Res Pract 2012:506382

74. Simon M, Braune S, Frings D, Wiontzek AK, Klose H, Kluge S (2014) High-flow nasal cannula oxygen versus non-invasive ventilation in patients with acute hypoxaemic respiratory failure undergoing flexible bronchoscopy-a prospective randomised trial. Crit Care 18:712

75. World Health Organization (2014) Obesity and overweight. WHO, Geneva

76. Jones RL, Nzekwu MM (2006) The effects of body mass index on lung volumes. Chest 130:827-833

77. Lin CK, Lin CC (2012) Work of breathing and respiratory drive in obesity. Respirology 17:402-411

78. Fernandez-Bustamante A, Hashimoto S, Serpa Neto A, Moine P, Vidal Melo MF, Repine JE (2015) Perioperative lung protective ventilation in obese patients. BMC Anesthesiol 15:56

79. Adams JP, Murphy PG (2000) Obesity in anaesthesia and intensive care. Br J Anaesth 85:91-108

80. Parke R, McGuinness S, Eccleston M (2009) Nasal high-flow therapy delivers low level positive airway pressure. Br J Anaesth 103:886-890

81. Dysart K, Miller TL, Wolfson MR, Shaffer TH (2009) Research in high flow therapy: mechanisms of action. Respir Med 103:1400-1405

82. Heinrich S, Horbach T, Stubner B, Prottengeier J, Irouschek A, Schmidt $J$ (2014) Benefits of heated and humidified high flow nasal oxygen for preoxygenation in morbidly obese patients undergoing bariatric surgery: a randomized controlled study. J Obes Bariatr 1:1-7

83. Nagata K, Morimoto T, Fujimoto D, Otoshi T, Nakagawa A, Otsuka K, Seo R, Atsumi T, Tomii K (2015) Efficacy of high-flow nasal cannula therapy in acute hypoxemic respiratory failure: decreased use of mechanical ventilation. Respir Care 2015:04026

84. Rittayamai N, Tscheikuna J, Praphruetkit N, Kijpinyochai S (2015) Use of high-flow nasal cannula for acute dyspnea and hypoxemia in the emergency department. Respir Care 2015:03837 